\title{
PENENTUAN NILAI MIC (MINIMUM INHIBITORY CONCENTRATION) DAN MKC MINIMUM KILLING CONCENTRATION) EKSTRAK DAUN KECOMBRANG (Etlingera elatior) TERHADAP Candida albicans PENYEBAB KEPUTIHAN
}

\author{
Alfrida Monica Salasa ${ }^{1}$, St. Ratnah ${ }^{2 *}$, H. Ismail Ibrahim ${ }^{3}$ \\ 1,2,3Jurusan Farmasi Poltekkes Kemenkes Makassar \\ "Koresponden : mansjurratnah@yahoo.com
}

DOI: https://doi.org/10.32382/mf.v15i1.781

\section{ABSTRAK}

Tanaman Kecombrang memiliki kandungan kimia seperti alkaloid, flavonoid, polifenol,steroid, saponin, dan minyak atsiri. Kandungan senyawa fitokimia pada tanaman diketahui mempunyai peranan yang sangat penting bagi kesehatan termasuk fungsinya dalam pencegahan terhadap penyakit. Tujuan dari penelitian ini adalah untuk menentukan nilai MIC (Minimum Inhibitory Concentration) dan MKC (Minimum Killing Concentration) dari Ekstrak Daun Kecombrang (Etlingera elatior) terhadap pertumbuhan Candida albicans dengan metode dilusi cair. Penelitian ini merupakan eksperimen murni menggunakan ekstrak daun kecombrang lalu ditentukan nilai MIC dan MKC dengan menggunakan metode dilusi cair. Konsentrasi yang digunakan adalah $1,25 \% ; 2,5 \% ; 3,75 \% ; 5 \% ; 6,25 \% ; 7,5 \% ; 8,75 \% ; 10 \% ; 12,5 \% ; 15 \% ; 17,5 \%$; $20 \% ; 22,5 \% ; 25 \%$ b/v. Hasil penelitian menunjukkan bahwa nilai MIC (Minimum Inhibitory Concentration) ekstrak Daun Kecombrang terdapat pada konsentrasi 6,25\% b/v dan nilai MKC (Minimum Killing Concentration) terdapat pada konsentrasi 8,75\% b/v. Hal ini menunjukkan bahwa ekstrak Daun Kecombrang (Etlingera elatior) efektif untuk menghambat dan membunuh jamur Candida albicans.

\section{Kata kunci : MIC, MKC, Ekstrak Daun Kecombrang, Candida albicans}

\section{PENDAHULUAN}

Indonesia merupakan negara tropis dengan potensi tanaman yang secara turun temurun digunakan sebagai obat tradisional. Terdapatnya trend back to nature mengakibatkan masyarakat semakin menyadari pentingnya penggunaan bahan alami bagi kesehatan. Masyarakat semakin memahami keunggulan penggunaan obat tradisional, antara lain: harga yang lebih murah, kemudahan dalam memperoleh produk, dan mempunyai efek samping yang minimal (Murdopo, 2014).

Salah satu tanaman yang dapat digunakan sebagai obat tradisional tersebut adalah Kecombrang (Etlingera elatior). Kecombrang merupakan salah satu jenis tanaman rempah - rempah asli Indonesia yang termasuk dalam famili Zingiberaceae, masyarakat di daerah Luwu menggunakan Buah Kecombrang sebagai bumbu masak, juga secara tradisional digunakan sebagai obat-obatan.

Beberapa tahun terakhir ini, tanaman Kecombrang mendapat perhatian sangat besar karena adanya fakta empiris serta bukti penelitian ilmiah, Bunga Kecombrang memiliki kandungan kimia seperti alkaloid, flavonoid, polifenol,steroid, saponin, dan minyak atsiri. Kandungan senyawa fitokimia pada tanaman diketahui mempunyai peranan yang sangat penting bagi kesehatan termasuk fungsinya dalam pencegahan terhadap penyakit (Tampubolon et al., 1983; Winarti dan Nurdjanah, 2005). Penelitian terhadap Bunga dan Buah Kecombrang telah dilakukan oleh Habsah $e t$ al. (2005) bahwa Kecombrang dapat dipakai untuk mengobati beberapa penyakit infeksi dan penyakit degenerative seperti kanker dan tumor. Menurut Hudaya, (2010) dan Akbar (2008) Kecombrang memiliki aktivitas antibakteri dan antioksidan (Muawanah, A., et al, 2012). Selain itu Kecombrang sebagai penghilang bau badan (Sirait. N., 2008). Menurut Jafar et al., (2007) Kecombrang mengandung minyak esensial yang bersifat bioaktif (daun $0,0735 \%$; bunga $0,0334 \%$; batang $0,0029 \%$ dan rhizome $0,0021 \%)$. Menurut Naufalin et 
al., (2005) zat antibakteri dari ekstrak etanol dan etil asetat dari bunga Kecombrang dapat menghambat berbagai bakteri seperti Bacillus cereus, $P$. aeroginosa, $S$. typhimurium, dan Eschericia coli. Menurut Ismail dkk (2017) menunjukkan bahwa hasil fraksinasi Ekstrak Daun Kecombrang (Etlingera elatior) memiliki potensi antimikroba terhadap Candida albicans penyebab keputihan pada ibu hamil.

Pada penelitian ini akan dilakukan penentuan Nilai MIC (Minimum Inhibitory Concentration) dan MKC (Minimum Killing Concentration) Ekstrak Daun Kecombrang Terhadap Candida albicans Penyebab Keputihan. Pengujian penetuan nilai MIC dan MKC dilakukan dengan menggunakan metode dilusi cair. Hasil penelitian ini akan ditentukan konsentrasi terendah dari Ekstrak Daun Kecombrang dalam menghambat dan membunuh Candida albicans penyebab keputihan. Rumusan masalah pada penelitian ini adalah berapa besar konsentrasi ekstrak Daun Kecombrang (Etlingera elatior) yang efektif terhadap pertumbuhan Candida albicans dengan metode dilusi cair ?. Tujuan penelitian ini adalah untuk menentukan nilai MIC (Minimum Inhibitory Concentration) dan MKC (Minimum Killing Concentration) dari Ekstrak Daun Kecombrang (Etlingera elatior) terhadap pertumbuhan Candida albicans dengan metode dilusi cair.

\section{METODE}

\section{Jenis Penelitian}

Jenis penelitian yang digunakan adalah penelitian eksperimental laboratorium dengan menentukan nilai MIC dan MKC Ekstrak Daun Kecombrang Terhadap Candida albicans penyebab keputihan pada ibu hamil dengan metode dilusi cair.

\section{Waktu dan Tempat Penelitian}

Penelitian ini telah dilakukan pada bulan Mei - Juli 2018, di Laboratorium Biologi Farmasi Jurusan Farmasi Politeknik Kesehatan Kemenkes RI Makassar

\section{Bahan Uji dan Sampel Penelitian}

Bahan uji pada penelitian ini adalah Daun Kecombrang (etlingera elatior) berupa daun kelima dari pucuk sampai daun yang tidak kuning (sehat), yang diambil pada pagi hari. Sedangkan sampel penelitian adalah Candida albicans.

\section{Parameter yang akan diukur}

Parameter uji pada penelitian ini adalah penentuan Minimum Inhibitory Concentration (MIC) berupa nilai optical density (OD), sedangkan penentuan Minimum Killing Concentration (MKC) yang diamati yaitu dengan melihat ada atau tidaknya pertumbuhan koloni bakteri pada konsentrasi tertentu pada media.

\section{Alat dan Bahan}

Alat - alat yang digunakan adalah bejana maserasi, tabung reaksi, cawan petri, pipet tetes, pipet ukur, bunsen, ose bulat dan lurus, pinset, mikroskop, timbangan analitik, inkubator, kulkas, batang pengaduk, erlenmeyer, beaker gelas, autoclave, spidol marker, gelas objek. Sedangkan bahan penelitian yang digunakan adalah biakan murni Candida albicans, Ekstrak Daun Kecombrang (Etlingera elatior), air suling, Sabaroud Dextrose Broth (SDB), Sabaroud Dextrosa Agar (SDA), aquadest steril, Mc Farlan 0,5.

\section{Pengolahan dan Estraksi Daun Kecombrang}

Daun Kecombrang terlebih dahulu dibuat simplisia kemudian diekstraksi dengan metode maserasi dengan menggunakan pelarut etanol 96\%. Ekstrak etanol yang diperoleh dikumpulkan kemudian diuapkan dengan rotavapor dan dikeringkan di atas penangas air, hingga diperoleh ekstrak kering.

\section{Penyiapan Jamur Candida albicans}

Dilakukan peremajaan jamur dengan cara mengambil dari stok murni diambil 1 ose dan diinokulasi dengan cara digoreskan ke dalam medium SDA miring kemudian diinkubasi dalam inkubator pada suhu $25^{\circ} \mathrm{C}$ selama 24 jam. Kemudian diambil satu ose jamur yang telah diremajakan, kemudian dimasukkan ke dalam tabung reaksi yang telah berisi $3-4 \mathrm{~mL}$ air steril sehinggatingkat kekeruhannya sama dengan McFarland 0,5 (setara dengan 1,5 x $10^{6}$ kuman), dikocok perlahan agar homogen dan suspensi siap digunakan. 
Penyiapan Bahan Uji

Bahan uji dibuat dengan mengencerkan ekstrak Daun Kecombrang (Etlingera elatior) dengan pelarut $\mathrm{Na} \mathrm{CMC}$ steril. Konsentrasi bahan uji yang digunakan adalah $1,25 \% ; 2,5 \% ; 3,75 \%$; 5\%; 6,25\%; $7,5 \% ; 8,75 \% ; 10 \% ; 12,5 \% ; 15 \% ; 17,5 \%$; $20 \% ; 22,5 \% ; 25 \% \mathrm{~b} / \mathrm{v}$

\section{Penentuan Nilai MIC dan MKC}

Disiapkan 17 tabung reaksi dan diisikan masing-masing $5 \mathrm{ml}$ Media Sabaroud Glucose Broth (SGB). Tabung 1 ditambahkan $1 \mathrm{ml}$ Ekstrak Daun Kecombrang 1,25\% dan 5 unit suspensi jamur Candida albicans. Tabung 2 ditambahkan $1 \mathrm{ml}$ Ekstrak Daun Kecombrang 2,5\% dan 5 unit suspensi jamur Candida albicans. Tabung 3 ditambahkan 1 ml Ekstrak Daun Kecombrang 3,75\% dan 5 unit suspensi jamur Candida albicans. Tabung 4 ditambahkan $1 \mathrm{ml}$ Ekstrak Daun Kecombrang 5\% dan 5 unit suspensi jamur Candida albicans. Tabung 5 ditambahkan $1 \mathrm{ml}$ Ekstrak Daun Kecombrang 6,25\% dan 5 unit suspensi jamur Candida albicans. Tabung 6 ditambahkan $1 \mathrm{ml}$ Ekstrak Daun Kecombrang 7,5\% dan 5 unit suspensi jamur Candida albicans. Tabung 7 ditambahkan 1 ml Ekstrak Daun Kecombrang 8,75\% dan 5 unit suspensi jamur Candida albicans. Tabung 8 ditambahkan $1 \mathrm{ml}$ Ekstrak Daun Kecombrang 10\% dan 5 unit suspensi jamur Candida albicans. Tabung 9 ditambahkan 1 ml Ekstrak Daun Kecombrang 12,5\% dan 5 unit suspensi jamur Candida albicans. Tabung 10 ditambahkan $1 \mathrm{ml}$ Ekstrak Daun Kecombrang 15\% dan 5 unit suspensi jamur Candida albicans. Tabung 11 ditambahkan $1 \mathrm{ml}$ Ekstrak Daun Kecombrang 17,5\% dan 5 unit suspensi jamur Candida albicans. Tabung 12 ditambahkan $1 \mathrm{ml}$ Ekstrak Daun Kecombrang 20\% dan 5 unit suspensi jamur Candida albicans. Tabung 13 ditambahkan $1 \mathrm{ml}$ Ekstrak Daun Kecombrang 22,5\% dan 5 unit suspensi jamur Candida albicans. Tabung 14 ditambahkan $1 \mathrm{ml}$ Ekstrak Daun

\section{HASIL}

Penentukan nilai MIC (Minimum Inhibitory Concentration) dan MKC (Minimum Killing Concentration) dari Ekstrak Daun Kecombrang (Etlingera elatior) terhadap pertumbuhan Candida albicans dengan metode dilusi cair. Hasil
Kecombrang 25\% dan 5 unit suspensi jamur Candida albicans. Tabung 15 sebagai kontrol obat $(\mathrm{K}+)$ diisi $5 \mathrm{ml}$ media NB ditambahkan $1 \mathrm{ml}$ Nystatin 1000 iu kemudian ditambahkan 5 unit suspensi bakteri. Tabung 16 sebagai kontrol aquadest (K-) diisi $5 \mathrm{ml}$ media NB kemudian ditambahkan $1 \mathrm{ml}$ aquadest dan ditambahkan 5 unit suspensi bakteri. Tabung 17 sebagai kontrol media hanya diisi $5 \mathrm{ml}$ media NB.

Perlakuan di atas dilakukan pengulangan sebanyak empat kali, tetapi tabung ke 4 tidak ditambahkan jamur. Kesemua tabung diinkubasi pada suhu $25^{\circ} \mathrm{C}$ selama 18-24 jam, kemudian diamati. Konsentrasi terendah dari larutan sampel yang dapat menghambat pertumbuhan bakteri (ditandai dengan kejernihan secara visual oleh tiga pengamat secara independen) ditentukan sebagai Minimum Inhibitory Concentraction (MIC).

Untuk mengetahui Minimum Killing Concentraction (MKC), larutan diinkubasi lanjut pada suhu $25^{\circ} \mathrm{C}$ selama 2x24 jam. MKC ditentukan pada konsentrasi terendah dimana pada media tidak terdapat pertumbuhan koloni bakteri.

Dari metode ini dapat ditentukan konsentrasi MIC (Minimum Inhibitory Concentration) yaitu kadar terkecil dari ekstrak Daun Kecombrang yang dapat menghambat pertumbuhan Candida albicans Konsentrasi MKC (Minimum Killing Concentration) yaitu kadar terkecil dari Ekstrak Daun Kecombrang yang dapat membunuh pertumbuhan Candida albicans dari setiap percobaan/replikasi. Sehingga dari rata-rata tersebut kita dapat mengetahui nilai MIC (Minimum Inhibitory Concentration) dan MKC (Minimum Killing Concentration).

Parameter yang digunakan dalam penelitian adalah tingkat kekeruhan yang tidak berubah berdasarkan kontrol tabung yang berisi media dan Ekstrak Daun Kecombrang.

pengujian berupa pengamatan tingkat kekeruhan untuk menentukan nilai MIC (Minimum Inhibitory Concentration) dan nilai MKC (Minimum Killing Concentration) dari Ekstrak Daun Kecombrang (Etlingera elatior) terhadap pertumbuhan Candida albicans. Dengan masa inkubasi untuk penentuan nilai MIC 
(Minimum Inhibitory Concentration) adalah pada suhu $25^{\circ} \mathrm{C}$ selama $1 \times 24$ jam, sedangkan untuk penentuan nilai MKC (Minimum Killing Concentration)adalah pada suhu $25^{\circ} \mathrm{C}$ selama $2 \times 24 \mathrm{jam}$. Hasil pengujian nilai MIC dan MKC dapat dilihat pada tabel 1 dan tabel 2.

\section{PEMBAHASAN}

Bahan uji pada penelitian ini adalah Daun Kecombrang (Etlingera elatior) dari daerah Masamba Kabupaten Luwu Utara. Daun segar dipetik pada pagi hari, helaian daun yang masih utuh, berada pada urutan 35 dari pucuk, dicuci bersih dengan air mengalir, dipotong kecil-kecil, kemudian dikering-anginkan, selanjutnya disebut sebagai simplisia.

Simplisia sebanyak 250 gram diekstraksi secara maserasi menggunakan pelarut etanol 96\%, digunakan Etanol 96\% sebagai pelarut dimaksudkan agar semua senyawa kimia dalam simplisia yang polar maupun non polar dapat terekstraksi. Ekstrak cair yang diperoleh selanjutnya diuapkan dengan menggunakan rotavapor sampai diperoleh ekstrak kering. Pelarut dari ekstrak (Etanol), harus diuapkan agar tidak mempengaruhi sifar pelarut pada proses identifikasi dan isolasi, sehingga ekstrak diupayakan kering. Bila penguapan belum sempurna dari proses rotavapor, maka pengeringan dapat dilanjutkan dengan penangas air.

Ekstrak kental yang diperoleh diuji untuk menentukan nilai MIC (Minimum Inhibitory Concentration) dan nilai MKC (Minimum Killing Concentration) dengan metode dilusi cair. Minimum Inhibitory Concentraction (MIC) adalah konsentrasi minimal dari Ekstrak Daun Kecombrang yang dapat menghambat pertumbuhan Candida albicans. Minimum Killing Concentration (MKC) adalah konsentrasi minimal dari Ekstrak Daun Kecombrang yang dapat membunuh Candida albicans. Parameter yang digunakan adalah tingkat kekeruhan dari perlakuan dibandingkan dengan kontrol (perlakuan tanpa inokulasi bakteri). Konsentrasi ekstrak yang digunakan dalam penelitian ini adalah 1,25 $\% ; 2,5 \% ; 3,75 \% ; 5 \% ; 6,25 \% ; 7,5 \% ; 8,75 \%$; $10 \% ; 12,5 \% ; 15 \% ; 17,5 \% ; 20 \% ; 22,5 \%$; $25 \%$ b/v. Setiap konsentrasi ekstrak dimasukkan ke dalam tabung reaksi yang telah berisi media NB selanjutnya ditambahkan Candida albicans lalu diinkubasi pada suhu $25^{\circ} \mathrm{C}$ selama 1 × 24 jam untuk penentuan nilai MIC dan dilanjutkan lagi inkubasi selama 1 x 24 jam untuk penentuan nilai MKC.

Hasil penelitian untuk penentuan nilai MIC menunjukkan bahwa setelah inkubasi 1 x 24 jam konsentrasi $1,25 \%$; $2,5 \% ; 3,75 \% ; 5 \%$ b/v terdapat kekeruhan pada tabung reaksi yang memperlihatkan bahwa terdapat pertumbuhan Candida albicans pada media NB sedangkan pada konsentrasi $6,25 \%$ sampai $25 \%$ b/v tidak terdapat kekeruhan pada tabung reaksi yang memperlihatkan bahwa tidak ada pertumbuhan Candida albicans pada media NB. Hal ini menunjukkan bahwa nilai MIC dari ekstrak Daun Kecombrang adalah $6,25 \% \mathrm{~b} / \mathrm{v}$ (Tabel 1).

Hasil penelitian untuk penentuan nilai MKC menunjukkan bahwa setelah inkubasi 2 × 24 jam konsentrasi $1,25 \%$; $2,5 \% ; 3,75 \% ; 5 \% ; 6,25 \% ; 7,5 \%$ b/v terdapat kekeruhan pada tabung reaksi yang memperlihatkan bahwa terdapat pertumbuhan Candida albicans pada media NB sedangkan pada konsentrasi 8,75\% sampai $25 \% \mathrm{~b} / \mathrm{v}$ tidak terdapat kekeruhan pada tabung reaksi yang memperlihatkan bahwa tidak ada pertumbuhan Candida albicans pada media NB. Hal ini menunjukkan bahwa nilai MKC dari ekstrak Daun Kecombrang adalah 8,75\% b/v (tabel 2).

$\begin{array}{ccc}\text { Hasil penelitian } & \text { diatas } \\ \text { menunjukkan bahwa ekstrak } & \text { Daun }\end{array}$ Kecombrang memiliki efektifitas terhadap pertumbuhan Candida albicans penyebab keputihan. Hal ini disebabkan karena ekstrak daun keombrang mengandung beberapa senyawa fitokimia seperti saponin, flavonoid, polifenol dan minyak atsiri.

\section{KESIMPULAN}

Berdasarkan hasil penelitian yang dilakukan dapat disimpulkan bahwa nilai MIC (Minimum Inhibitory Concentration) ekstrak Daun Kecombrang terdapat pada konsentrasi 6,25\% b/v dan nilai MKC (Minimum Killing Concentration) terdapat pada konsentrasi $8,75 \%$ b/v. Hal ini menunjukkan bahwa ekstrak Daun Kecombrang (Etlingera elatior) efektif 
untuk menghambat dan membunuh jamur Candida albicans.

\section{SARAN}

Untuk penelitian lebih lanjut disarankan untuk menguji efektivitas Daun Kecombrang (Etlingera elatior) terhadap bakteri penyebab penyakit.

\section{DAFTAR PUSTAKA}

Akbar, J. 2008. Pemanfaatan Ekstrak Bunga Kecombrang (Nicolaia speciosa Horan) Terhadap Penyembuhan Infeksi Jamur Saprolegnia sp Pada Ikan Nila Merah.Jurnal Kalimantan Scientiae. Vol. XXVI (71) : 32-38.

Dwiatmini, K., et al. 2009. Induksi Mutasi Kecombrang (Etlingera elatior) Menggunakan Iradiasi Sinar Gamma. Journal Hortikultura. Vol. 19 No. 1. Hal: 1-5.

Ismail I. dkk, 2017, Uji Potensi Antimikroba Hasil Fraksinasi Ekstrak Daun Kecombrang (Etlingera Elatior) Terhadap Candida Albicans Penyebab Keputihan Pada Ibu Hamil, Penelitian Hibah Bersaing Poltekkes Kemenkes Makassar.

Jaffar F. M., C. P.Osman,. N.H. Ismail, and K. Awang. 2007. Analysis of Essential oils of leaves, stems, flowers, and Rhizomes of Etlingera elatior (JACK) R.M. SMITH. The Malaysian Journal of Analytical Scienses, Vol.11, Hal: 269-273.

Lay, Bibiana W. 2002. Analisis Mikroba Di Laboraturium. Jakarta : PT. Raja Grafindo Persada
Muawanah, A., et al., 2012. Penggunaan Bunga Kecombrang (Etlingera elatior) dalam Proses Fermentasi Permen Jelly. Jurnal Valensi Vol. 2 No. 4, Mei 2012 (526-533). ISSN : $1978-8193$.

Murdopo, (2014). Obat Herbal Tradisional. Jakarta: Ditjen Kementrian Perdagangan Republik Indonesia.

Naufalin. R., 2005. Kajian Sifat Antimkiroba Ekstrak Bunga Kecombrang (Nicolaia speciosa Horan) terhadap berbagai mikroba Patogen dan Perusak Pangan. Disertasi. Pascasarjana Institut Pertanian Bogor.

Sirait. N., 2008. Penggunaan Berbagai Jenis tanaman Obat untuk menanggulangi Bau Badan. Journal WARTA Penelitian dan Pengembangan Tanaman Industri Vol. 14 (3) Hal: 8-9.

Sudjaji. 1988. Metode Pemisahan. Penerbit Kanisius. Yogyakarta.

Tampubolon, O.T., S. Suhatsyah dan S.Sastrapradja. 1983. Penelitian Pendahuluan Kandungan Kimia Kecombrang (Nicolaia Speciosa Horan) dalam Risalah Simposium Penelitian Tumbuhan Obat III. Fakultas Farmasi UGM. DIY. Hal: 451-454.

Winarti, C dan Nurdjanah, N. 2005.Peluang Tanaman Rempah dan Obat Sebagai Sumber Pangan Fungsional. Jurnal Litbang Pertanian. Vol. 24(2) : 47-55. 
Tabel 1 : Hasil Pengujian MIC (Minimum Inhibitory Concentration) Ekstrak Daun Kecombrang (Etlingera elatior) Terhadap pertumbuhan Candida albicans.

Sumber : data primer Juni 2018

\begin{tabular}{|c|c|c|c|c|c|c|c|c|c|c|c|c|c|c|c|c|c|}
\hline \multirow{2}{*}{$\begin{array}{c}\text { Waktu } \\
\text { pengamatan }\end{array}$} & \multirow{2}{*}{ Tabung } & \multicolumn{14}{|c|}{ Konsentrasi ( \% b/v) } & \multirow{2}{*}{$\begin{array}{c}\mathbf{K} \\
(+)\end{array}$} & \multirow{2}{*}{$\begin{array}{l}\mathbf{K} \\
(-)\end{array}$} \\
\hline & & 1,25 & 2,5 & 3,75 & 5 & 6,25 & 7.5 & 8,75 & 10 & 12,5 & 15 & 17,5 & 20 & 22,5 & 25 & & \\
\hline \multirow{4}{*}{$\begin{array}{c}24 \mathrm{Jam} \\
\text { penanaman }\end{array}$} & 1 & + & + & - & + & - & - & - & - & - & - & - & - & - & - & - & + \\
\hline & 2 & + & + & - & - & - & - & - & - & - & - & - & - & - & - & - & + \\
\hline & 3 & + & + & + & - & - & - & - & - & - & - & - & - & - & - & - & + \\
\hline & 4 & - & - & - & - & - & - & - & - & - & - & - & - & - & - & - & - \\
\hline
\end{tabular}

Ket :

Tabung 1,2,dan 3 : Replikasi sampel

Tabung $4 \quad$ : Kontrol media

$\mathrm{K}(+) \quad$ : Kontrol positif (Nistatin $1000 \mathrm{iu})$

K (-) : Kontrol negatif (Natrium CMC)

: Terdapat kekeruhan pada media cair yang menandakan terdapat Pertumbuhan Candida albicans

- : Tidak terdapat kekeruhan pada media cair yang menandakan tidak terdapat Pertumbuhan Candida albicans 
Tabel 2 : Hasil Pengujian MKC (Minimum Inhibitory Concentration) Ekstrak Daun Kecombrang (Etlingera elatior) Terhadap pertumbuhan Candida albicans. Sumber : data primer Juni 2018

\begin{tabular}{|c|c|c|c|c|c|c|c|c|c|c|c|c|c|c|c|c|c|}
\hline \multirow{2}{*}{$\begin{array}{c}\text { Waktu } \\
\text { pengamatan }\end{array}$} & \multirow{2}{*}{ Tabung } & \multicolumn{14}{|c|}{ Konsentrasi (\% b/v) } & \multirow{2}{*}{$\begin{array}{c}\mathbf{K} \\
(+)\end{array}$} & \multirow{2}{*}{$\begin{array}{l}\mathbf{K} \\
(-)\end{array}$} \\
\hline & & 1,25 & 2,5 & 3,75 & 5 & 6,25 & 7.5 & 8,75 & 10 & 12,5 & 15 & 17,5 & 20 & 22,5 & 25 & & \\
\hline \multirow{4}{*}{$\begin{array}{c}48 \text { Jam } \\
\text { penanaman }\end{array}$} & 1 & + & + & - & + & + & + & - & - & - & - & - & - & - & - & - & + \\
\hline & 2 & + & + & - & - & + & + & - & - & - & - & - & - & - & - & - & + \\
\hline & 3 & + & + & + & - & - & + & - & - & - & - & - & - & - & - & - & - \\
\hline & 4 & - & - & - & - & - & - & - & - & - & - & - & - & - & - & - & + \\
\hline
\end{tabular}

Ket :

Tabung 1,2,dan 3 : Replikasi sampel

Tabung $4 \quad$ : Kontrol media

$\mathrm{K}(+) \quad:$ Kontrol positif (Nistatin $1000 \mathrm{iu})$

$\mathrm{K}(-) \quad$ : Kontrol negatif (Natrium CMC)

: Terdapat kekeruhan pada media cair yang menandakan terdapat Pertumbuhan Candida albicans

- : Tidak terdapat kekeruhan pada media cair yang menandakan tidak terdapat Pertumbuhan Candida albicans 